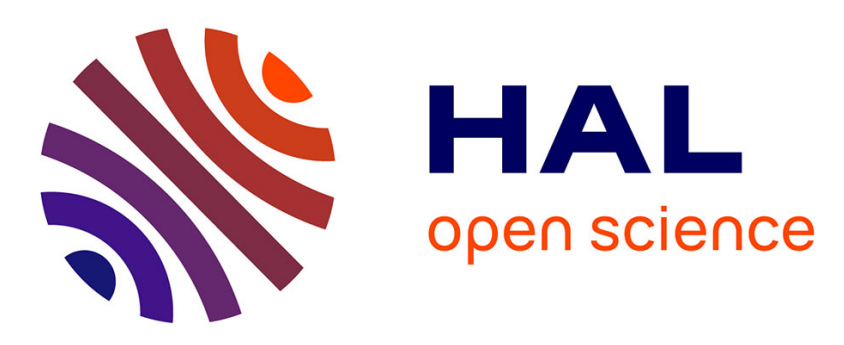

\title{
Caveat on the Actual Robustness of Heteronuclear NMR Methods for Probing the Surface of $\gamma$-Alumina and Related Catalysts
}

Kai C Szeto, Nicolas Merle, Julien Trébosc, Mostafa Taoufik, Régis M. Gauvin, Frédérique Pourpoint, Laurent Delevoye

\section{To cite this version:}

Kai C Szeto, Nicolas Merle, Julien Trébosc, Mostafa Taoufik, Régis M. Gauvin, et al.. Caveat on the Actual Robustness of Heteronuclear NMR Methods for Probing the Surface of $\gamma$-Alumina and Related Catalysts. Journal of Physical Chemistry C, 2019, 123 (20), pp.12919-12927. 10.1021/acs.jpcc.9b02634 . hal-03096856

\section{HAL Id: hal-03096856 https://hal.science/hal-03096856}

Submitted on 5 Jan 2021

HAL is a multi-disciplinary open access archive for the deposit and dissemination of scientific research documents, whether they are published or not. The documents may come from teaching and research institutions in France or abroad, or from public or private research centers.
L'archive ouverte pluridisciplinaire HAL, est destinée au dépôt et à la diffusion de documents scientifiques de niveau recherche, publiés ou non, émanant des établissements d'enseignement et de recherche français ou étrangers, des laboratoires publics ou privés. 


\section{A Caveat on the Actual Robustness of Heteronuclear NMR Methods for Probing the Surface of $\boldsymbol{\gamma}$-Alumina and Related Catalysts.}

Kai C. Szeto ${ }^{\mathrm{a}}$, Nicolas Merle ${ }^{\mathrm{b}}$, Julien Trébosc ${ }^{\mathrm{b}}$, Mostafa Taoufik ${ }^{\mathrm{a}}$, Régis M. Gauvin ${ }^{\mathrm{b}, *}$, Frédérique Pourpoint, ${ }^{\mathrm{b}}$ Laurent Delevoye ${ }^{\mathrm{b}, *}$.

${ }^{a}$ Laboratoire de Chimie, Catalyse, Polymères et Procédés, UMR 5265 CNRS/ESCPE-Lyon/UCBL, ESCPE Lyon, F-308-43, Boulevard du 11 Novembre 1918, F-69616 Villeurbanne Cedex, France.

${ }^{\mathrm{b}}$ Univ. Lille, CNRS, Centrale Lille, ENSCL, Univ. Artois, UMR 8181, UCCS - Unité de Catalyse et Chimie du Solide, F59000 Lille, France. 
ABSTRACT: Transitional aluminas are a very important class of materials in catalysis. The detailed understanding of their surface chemistry has attracted much attention with input from spectroscopic and theoretical studies. In this context, NMR is a key technique which, thanks to recent methodological developments, provides insights into local structure and relative arrangements. In the present paper, we first assess two ${ }^{1} \mathrm{H}_{-}{ }^{27} \mathrm{Al}$ heteronuclear correlation NMR methods for studying the surface of $\gamma-\mathrm{Al}_{2} \mathrm{O}_{3}$ dehydroxylated at $500{ }^{\circ} \mathrm{C}$. The commonly-used cross-polarization (CP) transfer method is compared to the D-HMQC (Dipolar Heteronuclear Multiple Quantum Coherence) experiment, revealing that the latter is significantly more robust and efficient with less signal distortion that hampers the recording of meaningful signals. Furthermore, a new MQ-D-HMQC pulse sequence is proposed to confirm the presence of sites, with a large quadrupolar coupling constant at the surface of alumina. The robustness of $D$-HMQC is further probed by two additional alumina-based catalysts, namely aluminum hydrides supported on $\gamma-\mathrm{Al}_{2} \mathrm{O}_{3}$, which are active in olefin hydrogenation and polymerization, and $\mathrm{ZrCp}_{2} \mathrm{Me}_{2}$ grafted onto $\gamma-\mathrm{Al}_{2} \mathrm{O}_{3}$, a single-site olefin polymerization catalyst. In both cases, this provides information on the configuration of surface aluminum species in the vicinity of catalytically active sites, and on the residual hydroxyl networks. The present study combines advanced NMR methods and complex catalytic materials for which a critical, yet fruitful, spectroscopic approach is required for deeper understanding. 


\section{Introduction}

Transitional aluminas, such as $\gamma-, \delta$ - or $\eta-\mathrm{Al}_{2} \mathrm{O}_{3}$, hold a prominent position as catalysis-related materials. ${ }^{1}$ They are currently used in several major industrial processes as catalysts or as catalyst supports. ${ }^{2}$ In this context where interfacial phenomena are instrumental, it is essential to understand their surface chemistry. As illustrated recently in a critical review by Busca, ${ }^{3}$ this topic has fueled debate for decades, owing to the complexity of these materials and the importance of experimental factors on their textural and spectroscopic features, to mention only a few. The reactivity of transitional aluminas owes much to the presence of both hydroxyl groups and Lewis acidic sites. The population of these two families (in terms of nature and density) strongly depends on the transitional phase (crystallinity) and on the thermal treatment the material was subjected to. A complex situation results from restructuration upon high temperature outgassing, a procedure which is typical for alumina activation prior to use in catalysis or catalyst preparation. This may occur via hydroxyl co-condensation or condensation with neighboring sites, forming new surface species. ${ }^{4,5}$ Experimental investigations on these systems have been performed with several distinct spectroscopic techniques. Considering the hydroxyl network, infrared spectroscopy has been routinely used to study these materials and their transformation, resulting in extensive literature on the topic. ${ }^{6}$ These elements, combined with theoretical / empirical considerations, have resulted in several contrasting assignments regarding the terminal or doubly/triply bridging character of the aluminum hydroxyl groups, and the coordination number of the Al centers involved. Among the other spectroscopic methods used in this context, solid-state NMR is a highly efficient technique that can afford structural information at the molecular level.

The alumina surface sites mainly concerned by this technique are the $\mathrm{AlOH}$, which can be amenable to both ${ }^{1} \mathrm{H}$ and ${ }^{27} \mathrm{Al}$ NMR, both nuclei being highly NMR-sensitive. Since De Canio's report on the ${ }^{1} \mathrm{H}$ NMR 
spectrum of $\gamma-\mathrm{Al}_{2} \mathrm{O}_{3}$, the chemical shift of the hydroxyl signal is known to be a good parameter to assess the terminal vs. bridging character. ${ }^{7}$ Furthermore, ${ }^{27} \mathrm{Al}$ MAS NMR is also suitable when investigating the local structure around the aluminum centers. Indeed, for this half-integer quadrupolar nucleus $(\mathrm{S}=5 / 2)$ with a $100 \%$ natural abundance, the ${ }^{27} \mathrm{Al}$ chemical shift is dependent on the coordination number, with tetra- $\left(\mathrm{Al}_{\mathrm{T}}\right)$, penta- $\left(\mathrm{Al} \mathrm{l}_{\mathrm{P}}\right)$, and hexa-coordinated $\left(\mathrm{Al}_{\mathrm{H}}\right)$ centers resonating around 60,40 and 0 ppm, respectively. Additionally, the determination of anisotropic parameters such as the quadrupolar coupling constant $\left(C_{\mathrm{Q}}\right)$, which results from the interaction of the electric quadrupolar moment of the nucleus with the electric field gradient, provides information on the local geometry in contrast to spin $1 / 2$ nuclei. The reliable assessment of the $C_{\mathrm{Q}}$ magnitude is thus essential. The ${ }^{27} \mathrm{Al}$ MAS NMR spectra are often broadened by the presence of the second-order quadrupolar coupling which affects the lineshape, unfortunately leading to strong overlapping of signals when dealing with multiple sites. The MQMAS experiment was thus proposed to separate the contributions of isotropic and anisotropic interactions, in order to retrieve both the chemical shift and quadrupolar parameters for each individual site. However, for the characterization of the $\gamma-\mathrm{Al}_{2} \mathrm{O}_{3}$ surface, MQMAS yields poor results as surface aluminum sites are lost in the dominant signal arising from these bulk aluminum sites (mostly tetra- and hexa-coordinated). When considering the issues associated with the study of catalysts where one has to probe the very surface of the material, an approach is needed that selectively provides the spectral data for the top layer(s) of Al centers. To achieve this, methods relying on ${ }^{1} \mathrm{H}$-magnetization transfer are particularly well suited thanks to the presence of hydroxyl groups at the surface of alumina. The most classical method derived from spin $1 / 2$ is Cross Polarization (CP)-MAS, which is used to characterize alumina-type materials. . $^{8-10}$ As described below in the case of $\gamma-\mathrm{Al}_{2} \mathrm{O}_{3}, \mathrm{CP}-\mathrm{MAS}$ is subject to severe limitations when applied to a quadrupolar nucleus such as ${ }^{27} \mathrm{~A} 1 .{ }^{12}$ An alternative method used to study alumina and derived materials is $D$-HMQC, which does not rely on spin-locking. ${ }^{13}$ It can be implemented with a dipolar recoupling scheme in order to highlight those sites which are in the vicinity of protons. ${ }^{14}$ Additionally, other recent pulse 
sequences, such as R-INEPT and PRESTO, are gaining interest as an alternative to transfer magnetization between ${ }^{1} \mathrm{H}$ and ${ }^{27} \mathrm{Al}$, but their application is still minor in the literature.

Regarding the characterization of complex materials, the impact of $1 \mathrm{D}$ data remains limited, owing to strong overlap of NMR signals from quadrupolar nuclei. All these methods can thus be adapted into a two-dimensional (2D) heteronuclear correlation (HETCOR) experiment, which is essential to obtain more detailed information. However, such heteronuclear correlations must be both efficient and robust. The latter point is critical when dealing with quadrupolar nuclei, for which lineshape analysis is a key element in the characterization process. When dealing with catalytically relevant surfaces, local constraints due to specific site structure may induce the occurrence of anisotropic parameters of high magnitude. It is therefore essential to be able to rely on methods that provide undistorted lineshapes for nuclei experiencing large quadrupolar coupling. Generally speaking, assignments and structural interpretations must be taken with extreme caution.

The first section of this contribution includes a critical assessment of the two most frequently used (on alumina-derived materials) sets of strategies, namely CP-MAS and D-HMQC, to reach through-space 2D HETCOR spectra when a half-integer quadrupolar nucleus is involved. In the following, special focus is placed on the robustness on both experiments rather than on sensitivity, which has been widely documented elsewhere. ${ }^{17,18}$ In particular, we show that for alumina-derived materials, even though $2 \mathrm{D}{ }^{1} \mathrm{H}-$ ${ }^{27} \mathrm{Al}$ CP-MAS spectra can be obtained within a reasonable time, the robustness of such experiments must be questioned when an overview of the materials surface is required. The efficiency of $D$-HMQC is also addressed and a new surface-selective ${ }^{27} \mathrm{Al}$ high-resolution pulse sequence is proposed to demonstrate the wide range of quadrupolar coupling constants experienced by the various ${ }^{27} \mathrm{Al}$ hydroxyl sites. In the second part, the robustness of the $D$-HMQC correlation sequence is demonstrated with two examples of $\gamma$-alumina-modified catalysts for applications in olefin polymerization and hydrogenation. We show that $D$-HMQC outperforms CP-MAS when dealing with systems featuring high $C_{\mathrm{Q}}$ values. 


\section{Experimental Methods}

The $\gamma$-alumina (from Rhône-Poulenc) was first calcined at $500{ }^{\circ} \mathrm{C}$ under a $\mathrm{N}_{2} / \mathrm{O}_{2}$ flow overnight, then partially dehydroxylated at $500^{\circ} \mathrm{C}$ under high vacuum $\left(10^{-5}\right.$ Torr $)$ for 12 hours. After this treatment, it was stored and handled in an argon-filled glove box. The specific surface area measured by BET $\left(\mathrm{N}_{2}\right)$ was 200 $\mathrm{m}^{2} \cdot \mathrm{g}^{-1}$. The XRD spectrum (Figure S1) clearly confirms the structural assignment as $\gamma-\mathrm{Al}_{2} \mathrm{O}_{3}$, in comparison with the diffraction pattern, and matches that of the reference 00-029-0063 $\left(\gamma-\mathrm{Al}_{2} \mathrm{O}_{3}\right)$ from ICDD (International Center for Diffraction Data). The infrared spectrum is also in line with reported data (Figure S2). ${ }^{2}$ Catalysts $\mathbf{A l}_{2} \mathbf{O}_{3}-\mathbf{H}$ and $\mathbf{A l}_{\mathbf{2}} \mathbf{O}_{3}-\mathbf{Z r}$ were synthesized as described in references 19 and 20 respectively.

For solid-state NMR analysis, the highly air-sensitive samples were packed into 3.2-mm zirconia rotors inside an Ar-filled glovebox, and sealed with tightly fitting Kel-F caps. ${ }^{1} \mathrm{H}$ MAS NMR, ${ }^{1} \mathrm{H}-{ }^{27} \mathrm{Al} \mathrm{CP}-\mathrm{MAS}$ NMR and ${ }^{1} \mathrm{H}^{-27} \mathrm{Al} D$-HMQC MAS NMR spectra were acquired on a Bruker Avance III 800 spectrometer $\left({ }^{1} \mathrm{H}, 800.13 \mathrm{MHz} ;{ }^{27} \mathrm{Al}\right.$ :, 208.50 MHz). For all experiments, the spinning frequency was $20 \mathrm{kHz}$. For ${ }^{1} \mathrm{H}$ MAS NMR spectra, 16 scans were collected using a $\pi / 2$ pulse excitation of $3.0 \mu$ s. For all ${ }^{1} \mathrm{H}^{-27} \mathrm{Al} \mathrm{CP}-$ MAS NMR, contact time was set at $1 \mathrm{~ms}$. Several Hartmann-Hahn conditions were scanned and are therefore specified in the corresponding figure captions. $D$-HMQC experiments were set up with an ${ }^{27} \mathrm{Al}$ spin echo selective to the central transition, with pulses of 8 and $16 \mu$ s, and a ${ }^{1} \mathrm{H} \pi / 2$ pulse of $3 \mu$ s on either side of the ${ }^{27} \mathrm{Al} \pi$ pulse. The SR 41 dipolar recoupling scheme ${ }^{21}$ was applied for $500 \mu$ s. The MQ- $D$ HMQC pulse sequence starts with two hard pulses of 3.0 and $1.25 \mu$ s at a radio-frequency (RF) field strength of $90 \mathrm{kHz}$ on the ${ }^{27} \mathrm{Al}$ channel, for triple-quantum excitation and reconversion respectively, followed by the $D$-HMQC scheme (with experimental parameters as stated above). 


\section{Results and Discussion}

\section{Critical assessment of CP vs. HMQC MAS NMR towards partially dehydrated $\gamma-\mathrm{Al}_{2} \mathrm{O}_{3}$ surface}

characterization

This section is devoted to the use of heteronuclear correlation methods in the case of $\mathrm{Al}_{2} \mathrm{O}_{3}-500$, i.e. $\gamma$ $\mathrm{Al}_{2} \mathrm{O}_{3}$ which has been subjected to dehydroxylation at $500{ }^{\circ} \mathrm{C}$ under vacuum for 12 hours. This is considered as a benchmark system, since such a treatment is classical in alumina-related catalytic studies. ${ }^{1,3,4}$ Its surface features different types of hydroxyl environments related to aluminium sites with various coordinations. For example, the surface aluminium sites can present $C_{\mathrm{Q}}$ values spreading over a large range from 4-6 MHz to a higher value of $12 \mathrm{MHz} .^{22}$ Of course, this does not rule out the possibility that other types of Al centers featuring larger quadrupolar coupling constants are present but not observed due to the broadness of their ${ }^{27} \mathrm{Al}$ NMR signal under our experimental conditions (magnetic field of 18.8 T, spinning speed of $20 \mathrm{kHz}$ ).

As mentioned above, we compare two of the main strategies (CP and D-HMQC) commonly applied to highlight ${ }^{1} \mathrm{H}-{ }^{27} \mathrm{Al}$ proximities. In particular, we critically assess their ability to provide bidimensional HETCOR spectra, which yield sound structural information.

The CP pulse sequence (Fig 1a) consists of a magnetization transfer through a spin-lock pulse, generally between the high gyromagnetic ratio nucleus (typically ${ }^{1} \mathrm{H}$, with $\left.\gamma_{\mathrm{H}}\right)$ and the low gyromagnetic one $\left(\gamma_{\mathrm{x}}\right)$, the gain being proportional to the ratio $\gamma_{\mathrm{H}} / \gamma_{\mathrm{X}}$. First, it provides signal enhancement and also allows correlations to be determined, as magnetization transfer operates via the dipolar coupling between the ${ }^{1} \mathrm{H}$ and $\mathrm{X}$ nuclei. However, it is well documented that the $\mathrm{CP}$ experiment suffers from several drawbacks, mainly owing to the complex spin dynamics of the quadrupolar nucleus $\mathrm{X}$ during spin-locking (vide infra). ${ }^{12,24}$ 
The ${ }^{1} \mathrm{H} \mathrm{T}_{1}$ relaxation delay is also a major factor when considering $\mathrm{CP}$ experiments. Indeed, the recycling delay between two transients must be about 3 to 5 times higher than the actual ${ }^{1} \mathrm{H} \mathrm{T}_{1}$ value. This is a key parameter when considering quantitative measurements. Based on our experience with such materials, we have frequently observed long to extremely long relaxation times for hydroxyl protons, with recycling delays reaching $1200 \mathrm{sec} .25-27$ This factor is very dependent on technical conditions, namely the possibility of adventitious introduction of air (i.e. of $\mathrm{O}_{2}$ and $\mathrm{H}_{2} \mathrm{O}$ ) in the rotor, for instance when spinning under an air flow with a loose rotor. In our studies, materials and catalysts were handled under rigorously inert conditions: the samples were handled strictly in the exclusion of air until being introduced into the stator, having packed the rotor in an argon-filled glovebox. However, we occasionally observed a $\mathrm{T}_{1}$ decrease upon extended residence time in the instrument when spinning under air, though with no detectable ${ }^{1} \mathrm{H}$ NMR spectrum difference. For instance, this is demonstrated in the case of $\mathrm{Al}_{2} \mathrm{O}_{3}-500$, where ${ }^{1} \mathrm{H} \mathrm{T}_{1}$ evolves from 130 to $45 \mathrm{sec}$ after 6 days of spinning in the magnet (Figure S3). This observation is due to the introduction of $\mathrm{O}_{2}$ in the rotor, with a paramagnetic effect on $\mathrm{T}_{1}{ }^{28-30}$ To our knowledge, there is no mention of such long recycling delays in the ${ }^{1} \mathrm{H}$ NMR studies on alumina-related materials reported in the literature. This may be due to insufficient attention to this parameter or most probably to short exposure to air upon sample preparation.

In most studies dedicated to the investigation of alumina surface, only 1D spectra have been recorded, which is of limited interest for structural analysis. Some of them even reported an incredibly high number of transients, i.e. several tens of thousands. ${ }^{31}$ Surprisingly, only a single article reported a $2 \mathrm{D}{ }^{1} \mathrm{H}-{ }^{27} \mathrm{Al} \mathrm{CP}-$ MAS spectrum of alumina. ${ }^{11}$ However, a quick look at the ${ }^{1} \mathrm{H}$ MAS NMR of the sample indicates the presence of large quantities of adsorbed water (signal at $4.5 \mathrm{ppm}$ ), giving rise to a fully hydrated surface with expected short relaxation times, while being detrimental to resolution in the ${ }^{1} \mathrm{H}$ dimension. With a material featuring short ${ }^{1} \mathrm{H} \mathrm{T}$, (dehydrated $\gamma$-alumina denoted $\mathrm{Al}_{2} \mathrm{O}_{3-500}{ }^{*}$, with ${ }^{1} \mathrm{H}$ NMR spectrum devoid of apparent differences with the pristine material, Figure S3), we were also able to record an ${ }^{1} \mathrm{H}-{ }^{27} \mathrm{Al}$ 
correlation spectrum using the ${ }^{1} \mathrm{H} \rightarrow{ }^{27} \mathrm{Al} \mathrm{CP}$-MAS pulse sequence (Figure 1, top), with a good signal-tonoise ratio and within a reasonable experimental time (15 hours). This spectrum features several correlations between various types of protons (with chemical shifts ranging from 0.5 to $4.5 \mathrm{ppm}$, thus corresponding to $\mu^{1}-\mathrm{HOAl}, \mu^{2}-\mathrm{HOAl}_{2}$ and $\mu^{3}-\mathrm{HOAl}_{3}$ ) and aluminum centers (with tetra-, penta- and hexacoordinated configurations). First, correlations emerge between specific pairs of proton and aluminum thanks to the resolution in the ${ }^{1} \mathrm{H}$ dimension. This provides a further layer of understanding compared to the 1D CP-MAS NMR spectrum (Figure 1b). The topology of the hydroxyl network in terms of the nature of the hydroxyls (terminal, doubly and triply bridging) and coordination number of aluminum $(4,5$ or 6$)$ can be obtained from this data. This was the case in a previous study by some of us on $\mathrm{Al}_{2} \mathrm{O}_{3-500}$, combining ${ }^{1} \mathrm{H}-{ }^{27} \mathrm{Al} D$-HMQC (see below) and ${ }^{1} \mathrm{H}-{ }^{1} \mathrm{H}$ DQ-SQ MAS NMR along with DFT calculations. ${ }^{22} \mathrm{~A}$ critical analysis of the ${ }^{27} \mathrm{Al}$ lineshapes extracted from the $2 \mathrm{D}$ correlation spectra is provided below when discussing the $D$-HMQC spectrum.

As discussed above, (very) long ${ }^{1} \mathrm{H}$ relaxation delays of several seconds up to $130 \mathrm{~s}$ (or more as observed in specific cases) are encountered when samples have not been exposed to a trace amount of air. When considering ${ }^{1} \mathrm{H} \rightarrow{ }^{27} \mathrm{Al} \mathrm{CP}$ as a magnetization transfer process, this is prejudicial to the recording of $\mathrm{CP}$ spectra of a sufficient $\mathrm{S} / \mathrm{N}$ ratio within a reasonable amount of time. An alternative approach to overcome the issue associated with large ${ }^{1} \mathrm{H} \mathrm{T}$ is to transfer magnetization from ${ }^{27} \mathrm{Al}$ to ${ }^{1} \mathrm{H}$, so that the recycling delay is set to ${ }^{27} \mathrm{Al} \mathrm{T}_{1}$, which is generally shorter than that of ${ }^{1} \mathrm{H}$. This should lead to the same heteronuclear correlation information as the ${ }^{1} \mathrm{H} \rightarrow{ }^{27} \mathrm{Al} \mathrm{CP}$ experiment though at the expense of signal intensity, as the gain is now given by the ratio $\gamma_{\mathrm{Al}} / \gamma_{\mathrm{H}}$. Figure 1 (bottom) shows ${ }^{27} \mathrm{Al} \rightarrow{ }^{1} \mathrm{H}$ CP-MAS correlation spectrum for $\mathrm{Al}_{2} \mathrm{O}_{3-500}$, which features a ${ }^{1} \mathrm{H} \mathrm{T}_{1}$ value of $130 \mathrm{~s}$. The correlation map is overall similar to that of the above-described ${ }^{1} \mathrm{H} \rightarrow{ }^{27} \mathrm{Al} \mathrm{CP}-\mathrm{MAS}$ spectrum. Most interestingly, recording the ${ }^{1} \mathrm{H} \rightarrow{ }^{27} \mathrm{Al} \mathrm{CP}-\mathrm{MAS}$ spectrum of this material would take a few months if one had to recycle every 3 to 5 times $\mathrm{T}_{1}$. 
a)
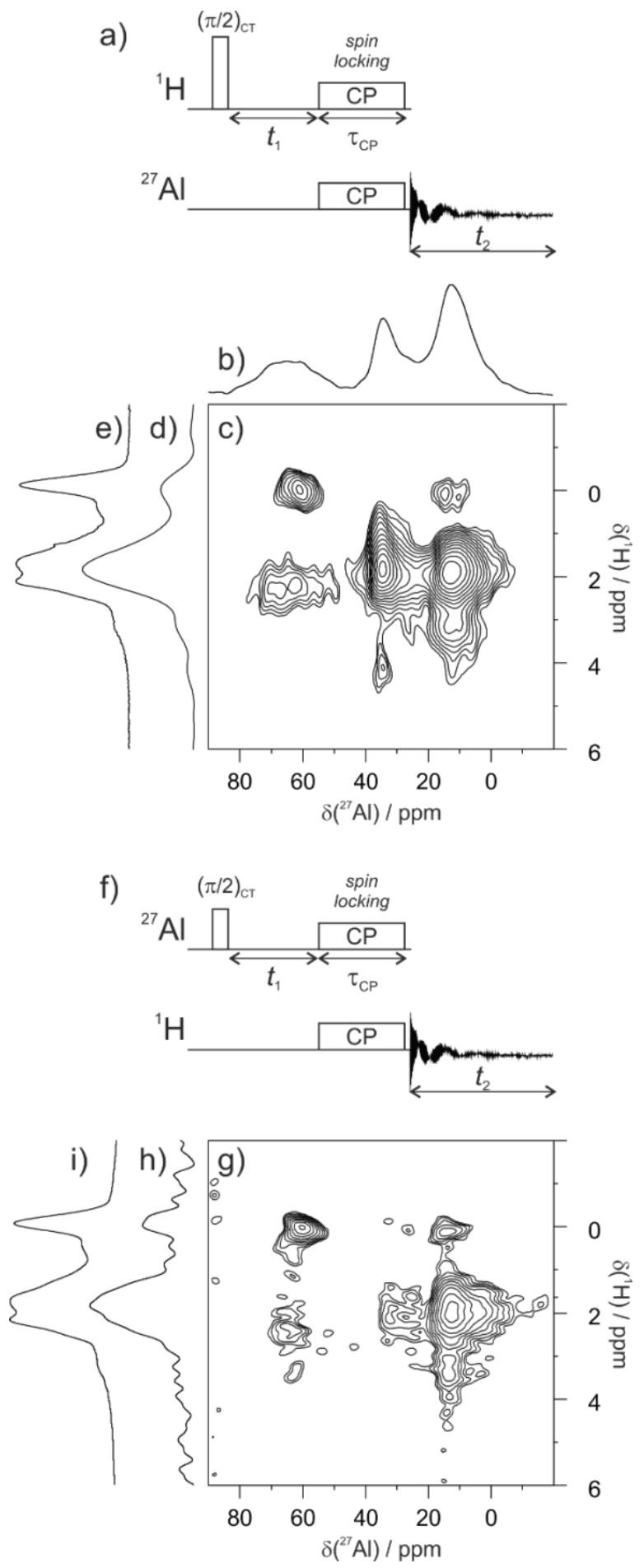

Figure 1. Top: ${ }^{1} \mathrm{H} \rightarrow{ }^{27} \mathrm{Al}$ spectra of $\mathrm{Al}_{2} \mathrm{O}_{3-500}{ }^{*}$. a) CP-MAS pulse sequence, b) $1 \mathrm{D}{ }^{27} \mathrm{Al}$ CP-MAS spectrum, c) 2D ${ }^{1} \mathrm{H} \rightarrow{ }^{27} \mathrm{Al} \mathrm{CP}-\mathrm{MAS}$ correlation spectrum and (d) ${ }^{1} \mathrm{H}$ projection. Bottom: ${ }^{27} \mathrm{Al} \rightarrow{ }^{1} \mathrm{H}$ spectra of $\mathrm{Al}_{2} \mathrm{O}_{3-500}$. f) $\mathrm{CP}-\mathrm{MAS}$ pulse sequence, g) $2 \mathrm{D}{ }^{27} \mathrm{Al} \rightarrow{ }^{1} \mathrm{H}$ CP-MAS correlation spectrum (Note that this 
spectrum was flipped so that ${ }^{27} \mathrm{Al}$ axis matches that of spectrum c) to facilitate side-by-side visual comparison) and h) 1D ${ }^{1} \mathrm{H}$ CP-MAS spectrum. (e) and (i) ${ }^{1} \mathrm{H}$ DEPTH MAS spectrum. Both 2D CP-MAS spectra were obtained in 15 hours (number of transients $=512$, recycling delay $\mathrm{D}_{1}=2 \mathrm{~s}$ ). The pulse sequence starts with a ${ }^{1} \mathrm{H} \pi / 2$ pulse of $2.65 \mu \mathrm{s}\left({ }^{1} \mathrm{H} \rightarrow{ }^{27} \mathrm{Al}\right)$ and a central-transition $(\mathrm{CT})$ selective ${ }^{27} \mathrm{Al} \pi / 2$ pulse of $8.5 \mu \mathrm{s}\left({ }^{27} \mathrm{Al} \rightarrow{ }^{1} \mathrm{H}\right)$, followed by Hartmann-Hahn conditions set to c) $v^{27} \mathrm{Al}, C T=44 \mathrm{kHz}, v^{1}{ }_{H}=24 \mathrm{kHz}$ and g) $v^{27} A l, C T=32 \mathrm{kHz}, v{ }_{H}=12 \mathrm{kHz}$, with the ${ }^{27} \mathrm{Al}$ carrier frequency at $40 \mathrm{ppm}$.

When dealing with materials as complex as aluminas and studying their surface, the CP approach quickly demonstrates its limitations. Indeed, and surprisingly enough since this is well known to groups proficient in using solid-state NMR for material analysis, optimization of the Hartmann-Hahn conditions when a quadrupolar nucleus is involved is not straightforward, so CP-MAS is definitely not a robust experiment. For instance, we recorded the 2D ${ }^{27} \mathrm{Al} \rightarrow{ }^{1} \mathrm{H} \mathrm{CP}$ MAS NMR spectra of $\mathrm{Al}_{2} \mathrm{O}_{3-500}$ using specifically chosen sets of experimental conditions, i.e. low and high power Hartmann-Hahn conditions and different ${ }^{27} \mathrm{Al}$ carrier frequencies (Figure S4).

The previous CP-MAS HETCOR spectra can also be compared to that obtained using the $D$-HMQC pulse sequence. It has been demonstrated on several occasions that the HMQC sequence is more robust than CP, especially at high magnetic field and high spinning frequency. ${ }^{18}$ In particular, the HMQC sequence avoids the spin locking period of $\mathrm{CP}$, which is a severe hurdle for quadrupolar nuclei. The $D$ HMQC spectrum of $\mathrm{Al}_{2} \mathrm{O}_{3}-500$, Figure 2 (top), is very informative as explained in a previous article where it was combined with ${ }^{1} \mathrm{H}-{ }^{1} \mathrm{H}$ DQSQ to propose a topology of the alumina surface. ${ }^{22}$ In short, each region of the ${ }^{1} \mathrm{H}$ spectrum, which corresponds to terminal $(-0.2-0.5 \mathrm{ppm})$, doubly $(0.8-2.5 \mathrm{ppm})$ and triply (2.5-6 ppm) bridging hydroxyls, gives rise to specific correlation patterns with ${ }^{27} \mathrm{Al}$ nuclei. The latter feature a diversity of sites which differ more by their quadrupolar coupling constant than by the chemical shift for a given coordination number $\left(\mathrm{Al}_{\mathrm{T}}, \mathrm{Al} \mathrm{l}_{\mathrm{P}}\right.$ or $\left.\mathrm{Al}_{\mathrm{H}}\right)$. Figure $\mathrm{S} 5$ gives an overview of the main families of aluminum environment, associated with their NMR parameters. 
We comment here only on the shape of the terminal hydroxyl group's signal, which shows a secondorder quadrupolar pattern with a quadrupolar coupling constant of $11.5 \mathrm{MHz}$, as deduced from the bestfit simulation (Figure 2c). The sites give rise to the most salient feature of the ${ }^{1} \mathrm{H}-{ }^{27} \mathrm{Al} D-\mathrm{HMQC}$ spectrum and are associated with the most reactive hydroxyl species of the $\mu^{1}-\mathrm{Al} \mathrm{T}-\mathrm{OH}$ type, which feature a $v(\mathrm{O}-\mathrm{H})$ stretching frequency of $3774 \mathrm{~cm}^{-1}$.22. They show higher reactivity compared to other $\mathrm{OH}$ groups, ${ }^{3,32,33}$ and some authors have proposed that they are located in the vicinity of Lewis acidic sites, which accounts for their specific reactivity. ${ }^{34}$ From the NMR point of view, the ${ }^{1} \mathrm{H}$ and ${ }^{27} \mathrm{Al}$ chemical shifts are not efficient descriptors for those reactive sites. In the present case, the latter show a large quadrupolar coupling constant, indicating severe local constraints, maybe due to a distorted tetra-coordinated $\mathrm{AlO}_{4}$ arrangement. 
a)
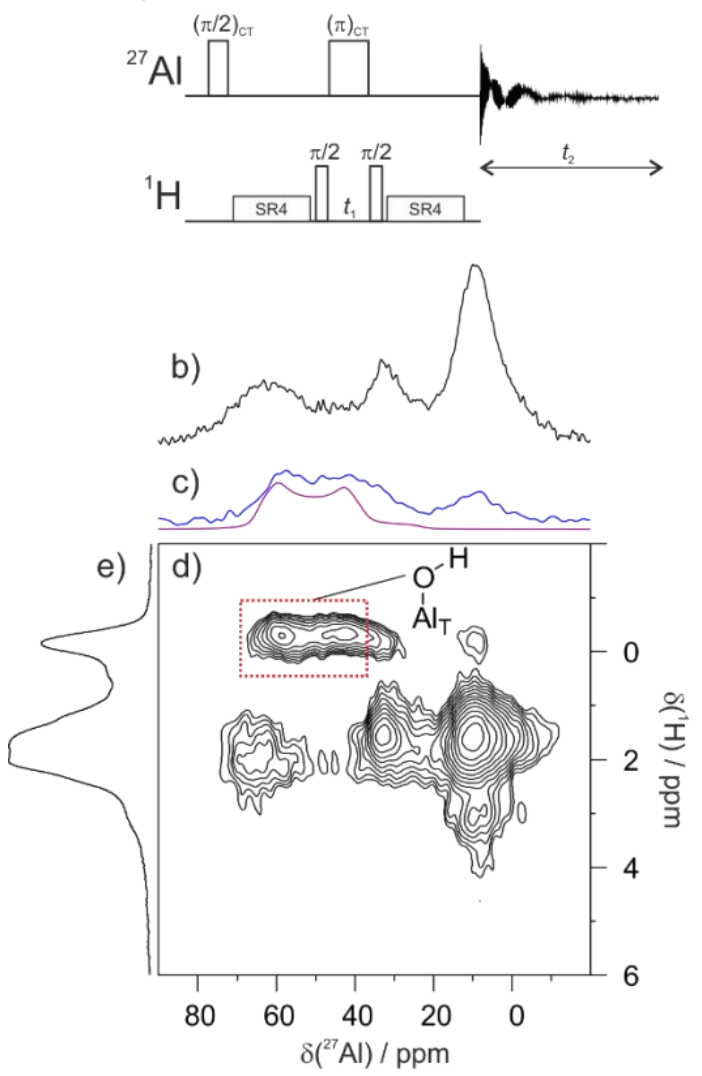

f)
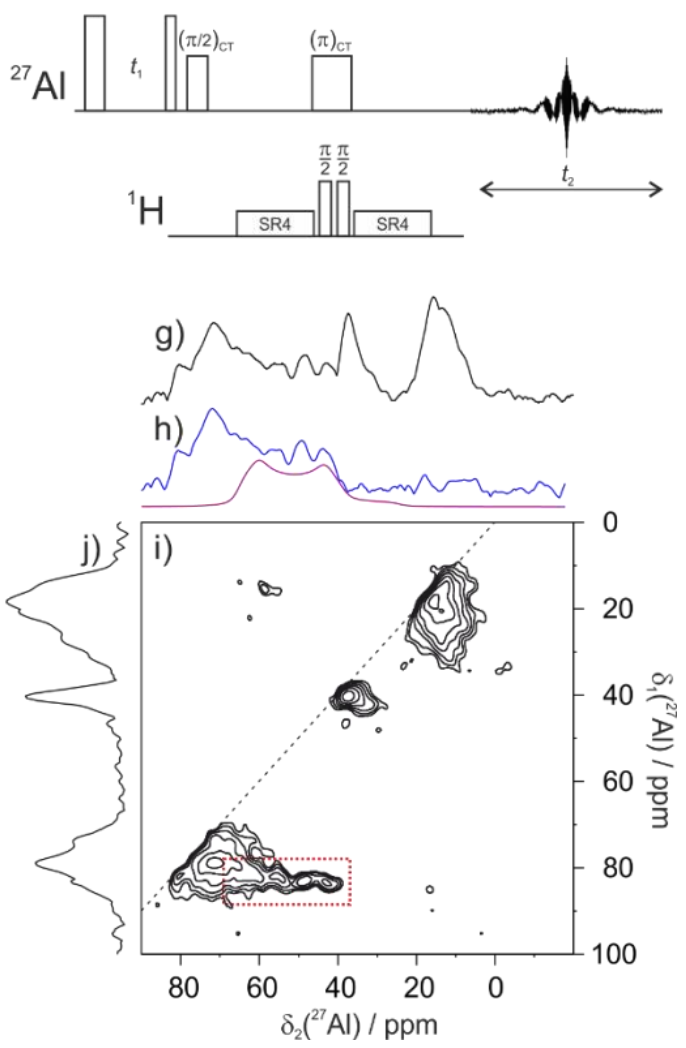
Figure 2: ${ }^{1} \mathrm{H}-{ }^{27} \mathrm{Al} D$-HMQC MAS NMR (top) and ${ }^{1} \mathrm{H}-{ }^{27} \mathrm{Al}$ MQ- $D$-HMQC MAS NMR spectra (bottom) of $\mathrm{Al}_{2} \mathrm{O}_{3-500}$ with (a, f) corresponding pulse sequences, b) ${ }^{27} \mathrm{Al}$ projection from ${ }^{1} \mathrm{H}$ range $\left.[-0.5,5 \mathrm{ppm}], \mathrm{c}\right)$ ${ }^{27} \mathrm{Al}$ projection of terminal hydroxyl groups, from ${ }^{1} \mathrm{H}$ range $[-0.5,0.5 \mathrm{ppm}]$ with best-fit simulation of AlT-OH sites $\left(\mathrm{CS}=69 \mathrm{ppm}, C_{\mathrm{Q}}=11.5 \mathrm{MHz}, \eta_{\mathrm{Q}}=0.26\right)$, d) $2 \mathrm{D}{ }^{1} \mathrm{H}_{-}{ }^{27} \mathrm{Al} D-\mathrm{HMQC}$ spectrum, e) ${ }^{1} \mathrm{H}$ DEPTH MAS spectrum, g) ${ }^{27} \mathrm{Al}$ MQ- $D$-HMQC projection, h) ${ }^{27} \mathrm{Al}$ MQ- $D$-HMQC projection of tetracoordinated aluminum sites with best-fit simulation of the Al $\mathrm{T}-\mathrm{OH}$ sites $\left(\mathrm{CS}=69 \mathrm{ppm}, \mathrm{C}_{\mathrm{Q}}=11.5 \mathrm{MHz}, \eta_{\mathrm{Q}}=0.26\right)$, i) 2D ${ }^{1} \mathrm{H}-{ }^{27} \mathrm{Al}$ MQ-D-HMQC spectrum, j) ${ }^{27} \mathrm{Al}$ isotropic dimension. Spectra were obtained in d) 18 hours (number of transients $=512$ for $64 \mathrm{t}_{1}$ increments, recycling delay $\mathrm{D}_{1}=2 \mathrm{~s}$ ) and $\mathrm{i}$ ) 38 hours (number of transients $=4944$ for $28 \mathrm{t}_{1}$ increments, recycling delay $\left.\mathrm{D}_{1}=1 \mathrm{~s}\right)$.

In Figure 3, we compare ${ }^{27} \mathrm{Al}$ slices extracted from heteronuclear correlation spectra of $\mathrm{Al}_{2} \mathrm{O}_{3-500}$ with the ${ }^{1} \mathrm{H}$ chemical shift of $-0.2 \mathrm{ppm}$, which accounts for terminal Al-OH (correlated with tetracoordinated and hexacoordinated aluminum at 60 and $10 \mathrm{ppm}$, respectively: Figure $3 \mathrm{a}$ is extracted from the ${ }^{1} \mathrm{H}-{ }^{27} \mathrm{Al}$ $D$-HMQC spectrum (Figure 2d), and Figure $3 \mathrm{~b}$ from the $2 \mathrm{D}{ }^{27} \mathrm{Al} \rightarrow{ }^{1} \mathrm{H} \mathrm{CP}$ MAS NMR spectrum (Figure 1c). The former (Figure 3a) has been modeled using a quadrupolar lineshape with a $C_{\mathrm{Q}}$ value above 11 $\mathrm{MHz}$. In the case of the CP extracted slice (Figure 3b), the lineshape cannot be fitted using a pure secondorder quadrupolar lineshape. The outcome was notably dependent on the experimental conditions, and particularly on the very influential position of the ${ }^{27} \mathrm{Al}$ carrier frequency. As cross-peaks were detected erratically (Figure S2), the lineshape appears as of either Gaussian or Czjzeck type (Figure 3b), or closer to a second-order quadrupolar coupled signal (Figure 3c), whether carrier frequency is set off or on resonance to the ${ }^{27} \mathrm{Al}$ tetracoordinated region. The tentative fit of the slice in Figure $3 \mathrm{c}$ (dashed line) with two Gaussian lineshapes is mathematically correct but structurally irrelevant. The solid line represents a poor simulation of this experimental lineshape, though being close to the actual NMR parameters, as deduced from the $D$-HMQC experiment. 
Based on CP HETCOR, all aluminum sites correlating with surface hydroxyls would show low quadrupolar couplings, below 6-7 MHz, which are values far below those obtained from $D$-HMQC or those reported from DFT calculations. ${ }^{31}$ This lineshape distortion is thus a major drawback of the CP approach, as shown in earlier studies. ${ }^{1}$
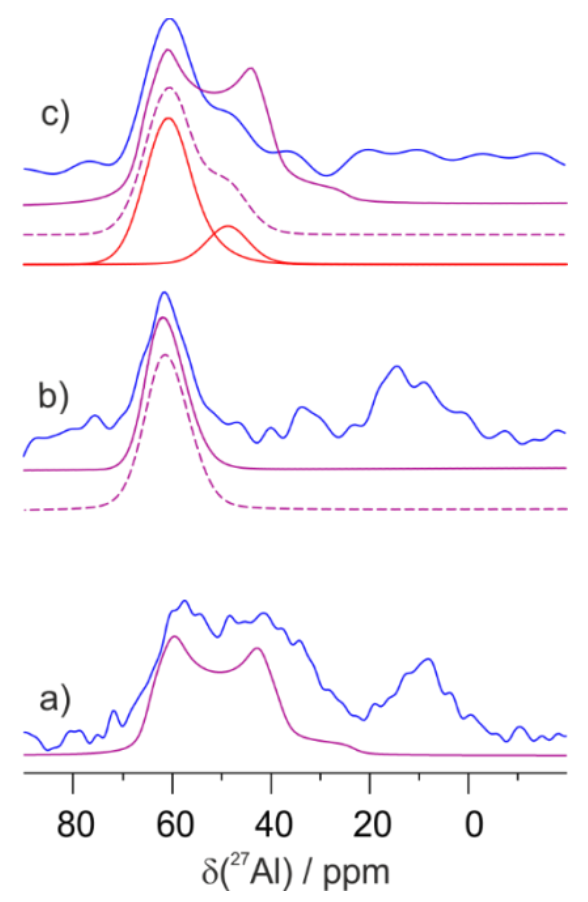

Figure 3. Slices extracted from heteronuclear correlation spectra of $\mathrm{Al}_{2} \mathrm{O}_{3-500}$ at ${ }^{1} \mathrm{H}$ chemical shift of $0.2 \mathrm{ppm}$ (terminal hydroxyl groups) from a) $2 \mathrm{D}{ }^{1} \mathrm{H}-{ }^{27} \mathrm{Al} D$-HMQC spectrum (Figure $2 \mathrm{c}$ ), b) $2 \mathrm{D}{ }^{27} \mathrm{Al} \rightarrow{ }^{1} \mathrm{H}$ CP-MAS spectrum (Figure S4a) and c) $2 \mathrm{D}{ }^{27} \mathrm{Al} \rightarrow{ }^{1} \mathrm{H}$ CP-MAS spectrum (Figure S4c). The best-fit simulations of the $\mathrm{Al}_{\mathrm{T}} \mathrm{OH}$ (in purple lines) were obtained with the following parameters: a) quadrupolar lineshape with $\mathrm{CS}=67 \mathrm{ppm}, C_{\mathrm{Q}}=11.5 \mathrm{MHz}$ and $\eta_{\mathrm{Q}}=0.26$; b) dash line: Gaussian lineshape with $\mathrm{CS}=61$ $\operatorname{ppm}(\mathrm{G} / \mathrm{L}=0.8)$; b) solid line: Czjzek lineshape with $\mathrm{CS}=63 \mathrm{ppm}, C_{\mathrm{Q}}=4 \mathrm{MHz}$ and $\Delta_{\mathrm{CS}}(\mathrm{CS}$ distribution $)=8$ ppm; c) dash line: two Gaussian lines with $\mathrm{CS}_{1}=62$ ppm and $\mathrm{CS}_{2}=49 \mathrm{ppm}(\mathrm{G} / \mathrm{L}=0.8)$ and solid line: quadrupolar lineshape with $\mathrm{CS}=71 \mathrm{ppm}, C_{\mathrm{Q}}=11.5 \mathrm{MHz}$ and $\eta_{\mathrm{Q}}=0.26$. 
Both $\mathrm{CP}$ and $D$-HMQC experiments under MAS conditions give rise to the correlation of ${ }^{1} \mathrm{H}$ and ${ }^{27} \mathrm{Al}$, with a low resolution in the quadrupolar nucleus dimension, i.e. retaining a broadening from the secondorder quadrupolar coupling. A further development of the MQMAS experiment, as previously attempted for $\mathrm{CP},{ }^{36}$ can be proposed here for the HMQC sequence. The MQMAS experiment provides a highresolution spectrum of half-integer quadrupolar nuclei by removing second-order quadrupolar broadening in the indirect dimension of a 2D spectrum. In Figure 2e, we present a new pulse sequence where the $D$ HMQC is preceded by a MQMAS filter. This results in a high-resolution ${ }^{27} \mathrm{Al}$ spectrum which provides information on the very first layer(s) of the alumina surface. The most striking element is the observation of a strongly quadrupolar coupled signal with no chemical shift distribution (red box in Figure 2h), which we assign to the $\mu^{1}$-HOAlT moiety. Best-fit simulations (using the dmfit program) are fully in line with the previously determined NMR parameters (chemical shift of about $69 \mathrm{ppm}, C_{\mathrm{Q}}$ value of about 11.5 $\mathrm{MHz}$, purple line in Figure $2 \mathrm{~g}$ ). This is direct evidence of the presence of strongly quadrupolar coupled $\mu^{1}$-HOAlT sites on the alumina surface.

\section{Probing the HMQC MAS NMR approach on $\gamma-\mathrm{Al}_{2} \mathrm{O}_{3}$ - supported catalytic systems}

In the previous section, we compared experimental data for an archetypical catalytic support using two strategies to reach ${ }^{1} \mathrm{H}-{ }^{27} \mathrm{Al}$ correlation spectra, namely CP-MAS and $D$-HMQC. We demonstrated that the CP-MAS approach is inappropriate to study alumina surface, having explored a large number of hydroxyl sites with different NMR characteristics. The main issue with CP-MAS is not so much related to the overall sensitivity of the sequence, since $2 \mathrm{D}$ correlation spectra can be obtained within acceptable experimental time, but rather to the reliability of the $\mathrm{CP}$ transfer. This leads to signal distortion or, worse, to signal loss. Any further reasoning based on such an approach is thus jeopardized.

The applicability of the HMQC when studying catalytically relevant materials was further exemplified in the case of alumina-supported aluminum hydride $\mathbf{A l}_{2} \mathbf{O}_{3}-\mathbf{H}$, which is used as an olefin polymerization 
and hydrogenation catalyst. ${ }^{19}$ This catalytic material has been prepared in two steps from $\gamma-\mathrm{Al}_{2} \mathrm{O}_{3}$, first by grafting of $\mathrm{Ali} i \mathrm{Bu}_{3}$, then by hydrogenolysis at high temperature $\left(400^{\circ} \mathrm{C}\right)$. This procedure, followed by mass balance analysis, elemental analysis and IR spectroscopy, affords an alumina-derived material devoid of surface hydroxyls, with Al-H sites as the sole type of surface protons. Such sites give rise to remarkable NMR features: indeed, the ${ }^{1} \mathrm{H}$ MAS NMR spectrum comprises an asymmetrical multiplet at 3.3 ppm which stems from the combination of 1$)$ a large scalar coupling with a spin $5 / 2$ nucleus $\left({ }^{1} J\left({ }^{1} \mathrm{H}-\right.\right.$ $\left.{ }^{27} \mathrm{Al}\right)=376 \mathrm{~Hz}$, assessed from $J$-resolved experiment), and 2) a large quadrupolar coupling constant for the $\mathrm{Al}$ center $\left(C_{\mathrm{Q}}\right.$ of about $15 \mathrm{MHz}$ ), giving rise to a second-order quadrupolar-dipolar cross-term (Figure 4a). ${ }^{37}$ Interestingly, this large $C_{\mathrm{Q}}$ value is unambiguous experimental proof of a quadrupolar coupling constant of a surface Al center. We previously studied $\mathbf{A l}_{2} \mathbf{O}_{3}-\mathbf{H}$ using the $J$-HMQC heteronuclear correlation experiment, and demonstrated that these hydride sites are mostly on tetra- and pentacoordinated $\mathrm{Al}$ centers. The $J$-HMQC sequence is selective, as it provides information through covalent bonds. In addition, we now use the complementary $D$-HMQC sequence to investigate the material through dipolar interaction and to probe the second coordination sphere of the aluminum hydrides. The $2 \mathrm{D}^{1} \mathrm{H}-{ }^{27} \mathrm{Al} D$-HMQC spectrum is presented in Figure $4 \mathrm{f}$. It features an intense correlation between the hydride signal at $3.3 \mathrm{ppm}$ (as evidenced from the ${ }^{27} \mathrm{Al}$-decoupled ${ }^{1} \mathrm{H}$ spectrum, Figure 4b) and the three types of $\mathrm{Al}$ centers $\left(\mathrm{Al}_{\mathrm{T}}, \mathrm{Al} \mathrm{l}_{\mathrm{P}}\right.$ and $\left.\mathrm{Al}_{\mathrm{H}}\right)$. This spectrum slightly differs from the $J$-HMQC correlation map (Figure S5). Indeed, as we rely on dipolar interactions, not only can we observe the Al-H fragments, but also the neighboring $\mathrm{Al}$ centers located in the second coordination sphere. This is clearly evidenced by comparing the $D$ - and $J$-filtered ${ }^{27} \mathrm{Al}$ NMR signals (Figure $4 \mathrm{~d}$ and e, respectively). It appears that the $D$-HMQC also reveals the contribution of the aluminum centers with lower $\mathrm{C}_{Q}$ values, which are mostly in tetra- and hexacoordinated configuration. This is evidenced by the sharper contributions at about 66 and 6 ppm (Figure 4e). Interestingly, the maxima of these two signals differ not only from that of the $\mathrm{Al}-\mathrm{H}$, but also from that of the $\mathrm{Al}_{\mathrm{T}}$ and $\mathrm{Al}_{\mathrm{H}}$ from the $\mathbf{A l}_{2} \mathbf{O}_{3}-\mathbf{H}$ material's ${ }^{27} \mathrm{Al}$ MAS NMR spectrum (Figure 
4c). This agrees with the fact that their chemical environment differs from that of the bulk, owing to their proximity with the surface. Furthermore, Alp are also observed, although to a lesser extent compared to the other two Al configurations. A tentative best-fit simulation is in line with this lineshape resulting from the combination of strongly quadrupolar coupled $\mathrm{Al}_{\mathrm{T}}$ and $\mathrm{Al}$ ( as first coordination sphere), along with bulk-like, distributed $\mathrm{Al}_{\mathrm{T}}$ and $\mathrm{Al}_{\mathrm{H}}$, with a significantly minor contribution from $\mathrm{Al}$ (see Figure S8). Additionally, 1D ${ }^{1} \mathrm{H} \rightarrow{ }^{27} \mathrm{Al} \mathrm{CP-MAS}$ spectra were also obtained for different Hartmann-Hahn conditions and carrier frequencies (Figure S9). The signal intensity is erratic and spectral lineshapes are occasionally distorted. Even if specific experimental conditions lead to a spectrum comparable to that obtained with $D$-HMQC, the lack of robustness for the CP-MAS experiment observed here is another argument against a broad applicability.

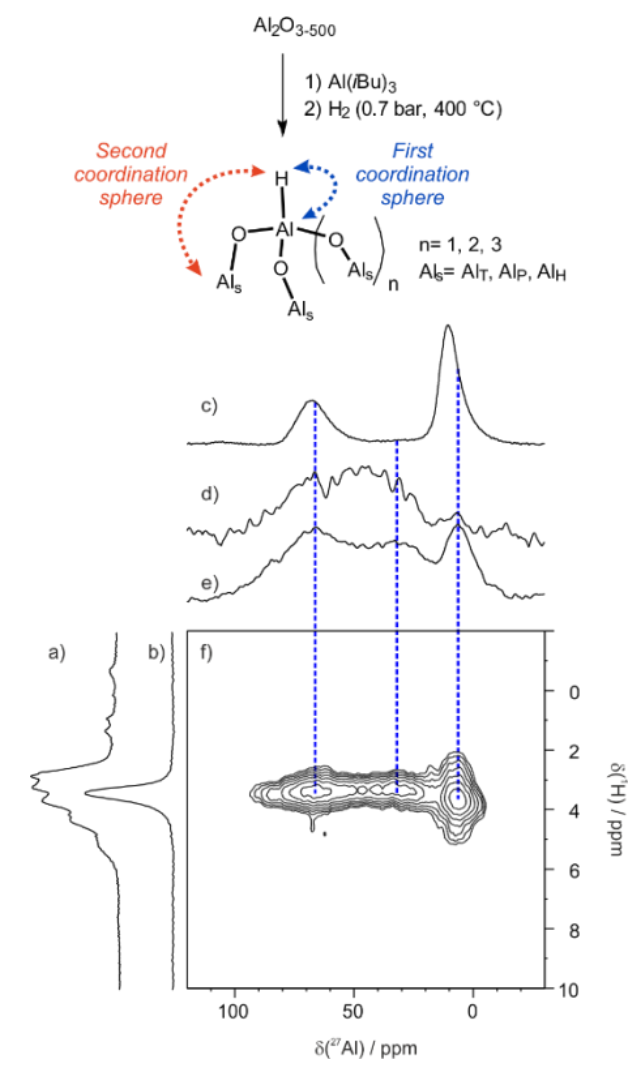

Figure 4. Synthesis and selected NMR data on $\mathbf{A l}_{2} \mathbf{O}_{3}-\mathbf{H}$ : a) ${ }^{1} \mathrm{H}$ MAS NMR, b) $\left\{{ }^{27} \mathrm{Al}\right\} J$-HMQC-filtered ${ }^{1} \mathrm{H}$ MAS spectrum with ${ }^{27} \mathrm{Al}$ RA-MP decoupling ${ }^{38}$, c) ${ }^{27} \mathrm{Al}$ MAS NMR, d) $\left\{{ }^{1} \mathrm{H}\right\} J$-HMQC-filtered ${ }^{27} \mathrm{Al}$ 
MAS NMR, e) $\left\{{ }^{1} \mathrm{H}\right\} D$-HMQC-filtered ${ }^{27} \mathrm{Al}$ MAS NMR and f) ${ }^{1} \mathrm{H}-{ }^{27} \mathrm{Al} 2 \mathrm{D} D$-HMQC MAS NMR spectra.

Spectrum in $\mathrm{f}$ ) was acquired in 21 hours (number of transients $=1536$ for $48 \mathrm{t}_{1}$ increments, recycling delay $\left.\mathrm{D}_{1}=1 \mathrm{~s}\right)$.

A further illustration of the versatility of the ${ }^{1} \mathrm{H}-{ }^{27} \mathrm{Al} D$-HMQC method for the detailed investigation of alumina-based catalysts can be found in the field of heterogeneous olefin polymerization catalysts. Group 4 metallocenes on various supports are used industrially in major (co)polymerization processes, and the structural studies on these catalysts are still a hot topic, especially when it comes to precise understanding of the nature of the interaction between the grafted organometallic fragment and the inorganic $\gamma-\mathrm{Al}_{2} \mathrm{O}_{3}$ support. ${ }^{39} \mathrm{Cp}_{2} \mathrm{ZrMe}_{2}\left(\mathrm{Cp}\right.$ : cyclopentadienyl) supported on $\gamma-\mathrm{Al}_{2} \mathrm{O}_{3-500}\left(\mathbf{A l}_{2} \mathbf{O}_{3}-\mathbf{Z r}\right)$ was previously studied using IR, mass balance analysis and EXAFS as well as ${ }^{1} \mathrm{H}$ MAS and ${ }^{13} \mathrm{C}$ CP MAS NMR. ${ }^{20}$ Even if its catalytic performances are modest compared to its best industrial counterparts, the characterization of such an archetypical system is highly relevant when investigating supported catalysts. However, so far, understanding of the interaction between these organometallic species and an inorganic support remains limited. To fill this gap, there is clearly a need for a robust heteronuclear correlation method that could provide insight into the nature of the Al centers surrounding the metallocene species and the residual hydroxyl network. In order to demonstrate the $D$-HMQC potential in alumina-based catalysts characterization, we focus here on the catalyst prepared from $\mathrm{Cp}_{2} \mathrm{Zr}\left(\mathrm{CD}_{3}\right)_{2}$. Compared to $\mathrm{Cp}_{2} \mathrm{Zr}\left(\mathrm{CH}_{3}\right)_{2}$, this simplifies the ${ }^{1} \mathrm{H}$ spectral data by avoiding overlap of the $\mathrm{Zr}$-Me signals with that of the residual Al$\mathrm{OH} \cdot{ }^{20}$ The ${ }^{1} \mathrm{H}$ NMR MAS spectrum of $\mathbf{A l}_{2} \mathbf{O}_{3}-\mathbf{Z r}$, (Figure 5a), is rather uninformative. It features an intense peak at $6.2 \mathrm{ppm}$, accounting for the cyclopentadienyl protons, and a broad, featureless signal from 0.5 to $5 \mathrm{ppm}$. On the contrary, the ${ }^{1} \mathrm{H}-{ }^{27} \mathrm{Al} D$-HMQC MAS NMR spectrum is very informative. It features cross-peaks for both $\mathrm{Cp}$ and hydroxyl protons, with distinct patterns. In the case of $\mathrm{Cp}$ protons, the corresponding ${ }^{27} \mathrm{Al}$ trace (Figure $5 \mathrm{c}$ ) provides a direct view of the neigboring aluminum centers: these are 
mostly tetra- and hexa-coordinated (in a rough 1:1 proportion). The pentacoordinated Al centers account for a minor yet significant share of the signal. The lineshape of the $\mathrm{Al}_{\mathrm{T}}$ and $\mathrm{Al} \mathrm{l}_{\mathrm{P}}$ denotes a strong quadrupolar coupling for these nuclei. This differs from the ${ }^{27} \mathrm{Al}$ MAS NMR signal of $\mathbf{A l}_{2} \mathbf{O}_{3}-\mathbf{Z r}$ (Figure $\mathrm{S} 10$ ), thus showing that the $D$-HMQC sequence filters the signal of the surface aluminum from that of the bulk. Along the same line, the weak, broad ${ }^{1} \mathrm{H}$ hydroxyl signal gives rise to correlations mostly with hexacoordinated aluminum centers, and to a lesser extent with tetra- and pentacoordinated Al (Figure 5d). The position of the signal in the ${ }^{1} \mathrm{H}$ dimension is in line with assignments as doubly and triply bridging hydroxyls (around 2 and 2.5-5 ppm, respectively). The distinctive terminal $\mathrm{Al}_{\mathrm{T}} \mathrm{OH}$ signal is no longer observed, indicating a full reaction of these sites. Therefore, we may conclude on the higher reactivity of the terminal hydroxyl (on $\mathrm{Al}_{\mathrm{T}}$ centers) and to a much lesser extent, doubly bridging groups (with a preference for those connected to $\mathrm{Al}_{\mathrm{T}}$ and $\mathrm{Al}$ ). This illustrates how this heteronuclear correlation can be harnessed to benefit from its robustness by revealing ${ }^{1} \mathrm{H}-{ }^{27} \mathrm{Al}$ proximities, with information on the $\mathrm{Al}$ site coordination. This provides further key information on the grafting sites. Clearly, in this example, a 1D ${ }^{1} \mathrm{H}-{ }^{27} \mathrm{Al}$ correlation spectrum (CP-MAS or $D$-HMQC filtered) could not provide such specific information by itself, while it is made possible with the $2 \mathrm{D}{ }^{1} \mathrm{H}-{ }^{27} \mathrm{Al} D$-HMQC. In addition, the precise reactivity pattern deduced from this spectroscopic evidence could not be deduced either from the ${ }^{1} \mathrm{H}$ MAS NMR only or from the infrared spectrum (Figure S11). 


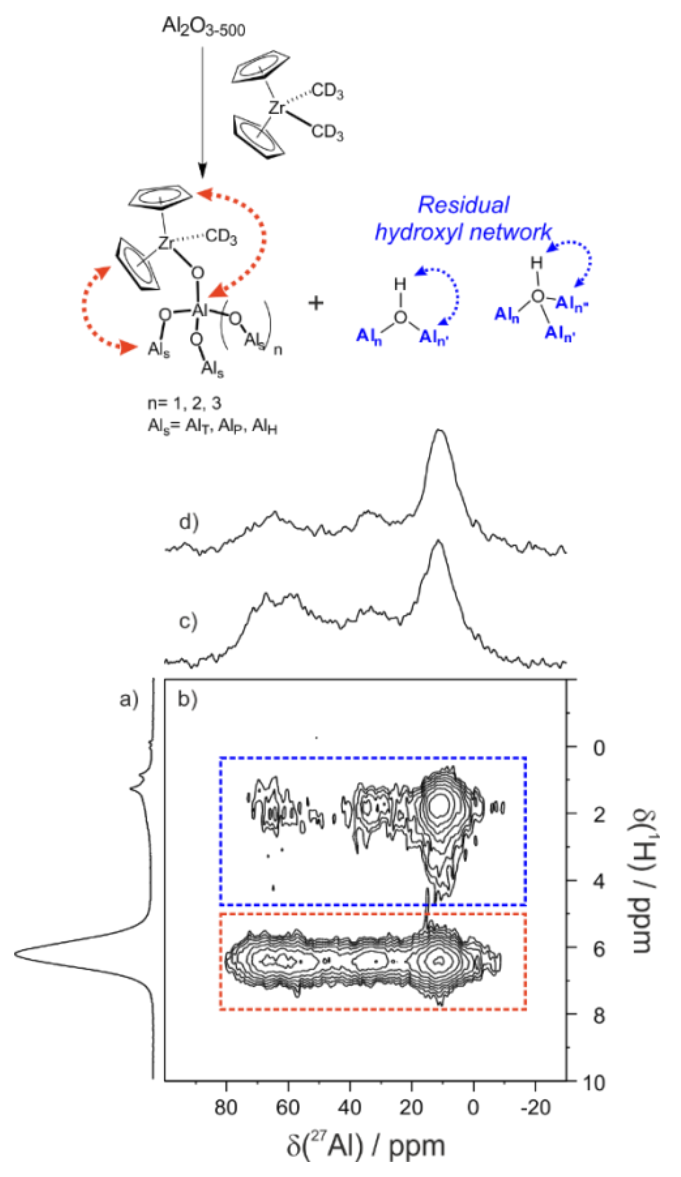

Figure 5. Synthesis and selected NMR data on $\mathbf{A l}_{2} \mathbf{O}_{3}-\mathbf{Z r}$ : a) ${ }^{1} \mathrm{H}$ MAS NMR, b) ${ }^{1} \mathrm{H}_{-}{ }^{27} \mathrm{Al} 2 \mathrm{D} D-\mathrm{HMQC}$ MAS NMR spectrum, c) sum of the ${ }^{27} \mathrm{Al}$ HMQC signal in the $[8-5 \mathrm{ppm}]{ }^{1} \mathrm{H}$ region, d) sum of the ${ }^{27} \mathrm{Al}$ HMQC signal in the $[5-0 \mathrm{ppm}]{ }^{1} \mathrm{H}$ region. Spectrum was acquired at $18.8 \mathrm{~T}$ with a spinning rate of 20 $\mathrm{kHz}$, in 17 hours (number of transients $=560$ for $54 \mathrm{t}_{1}$ increments, recycling delay $\mathrm{D}_{1}=2 \mathrm{~s}$ ).

\section{Conclusion}

Owing to their importance in major catalytic processes, transitional aluminas are attracting considerable attention, yet the nature of their surfaces is still a matter of debate. In this context, heteronuclear correlation methods in NMR are instrumental, as they afford molecular level information on both ${ }^{1} \mathrm{H}$ and ${ }^{27} \mathrm{Al}$ centers. Extensive discussion revolves around the anisotropic ${ }^{27} \mathrm{Al}$ NMR parameters, such as the quadrupolar coupling constants, which are considered as a major descriptor of the local configuration of 
the ${ }^{27} \mathrm{Al}$ nucleus. Our objective was to critically address the efficiency of two widely used methods (CP and $D$-HMQC), with a strong emphasis on their robustness, especially in terms of quadrupolar lineshape reproducibility.

We first show that the classical and most commonly used method, i.e. cross-polarization, does not meet the reproducibility criteria. Even if bidimensional spectra can be obtained, the outcome is severely dependent on the experimental conditions. It is clear that a quick analysis of the above-described 2D CPMAS correlation spectra, with a non-critical eye, would probably lead to some wrong conclusions about the local structure at the surface of alumina, or about the (in)visibility of the surface aluminum sites. This is clearly not acceptable for the widespread use of ${ }^{1} \mathrm{H} \rightarrow{ }^{27} \mathrm{Al} \mathrm{CP}-\mathrm{MAS}$ ( or ${ }^{27} \mathrm{Al} \rightarrow{ }^{1} \mathrm{H} \mathrm{CP}-\mathrm{MAS}$ ). In addition, we also confirm that lineshape distortion is a major drawback, an obvious fact for NMR spectroscopists. In spite of this, many papers in the field of materials characterization and catalysis rely extensively on this approach, even in very recent years.

On the other hand, the $D$-HMQC method, which does not rely on spin-locking of the quadrupolar nucleus, faithfully reproduces the structural complexity of an archetypical alumina surface. This was further exemplified in selected study examples of the surface of alumina-based catalysts by ${ }^{27} \mathrm{Al}$ NMR. $D$-HMQC as a heteronuclear method provides unambiguous, robust information regardless of the $C_{\mathrm{Q}}$ magnitude: on a spectrum, one can readily observe sites featuring $C_{\mathrm{Q}}$ values ranging from 5-6 MHz (bulklike signal) up to $15 \mathrm{MHz}$ (Al-H signal).D-HMQC approach has already provided unprecedented information on (modified) alumina surfaces.

From the wider perspective of partially dehydroxylated alumina surfaces and NMR studies of derived catalytic materials, the main issues do not concern the excitation of quadrupolar nuclei featuring (potentially) large $C_{\mathrm{Q}}$ values, but rather the frequency of the spectrometer, as high fields are mandatory when attempting to study such complex materials. Further work will include methodological and technical improvements for the implementation of INEPT and PRESTO in such a context. This should lead to 
further improvements in sensitivity compared to the HMQC experiment, maybe by considering the use of indirect proton detection. ${ }^{17,44}$ Progress can also be expected from current developments in Dynamic Nuclear Polarization (DNP), provided that 1) the gain achieved at high field is comparable to that obtained at moderate field, ${ }_{45}^{45}$ and 2) samples are not altered upon preparation with solvents and radicals, bearing in mind that $\gamma$-alumina surfaces are extremely sensitive to adsorption phenomena. From the catalytic materials point of view, there is a definite need to implement efficient and reliable methods that can take our understanding to new levels. The current hurdles include sensitivity or the ability to reproduce strongly quadrupolar-coupled sites, i.e. those that are considered as the most relevant to catalytic reactions.

\section{ASSOCIATED CONTENT}

Supporting Information. Additional experimental details and spectroscopic data. This material is available free of charge via the Internet at http://pubs.acs.org.

\section{AUTHOR INFORMATION}

\section{Corresponding Author}

* laurent.delevoye@univ-lille.fr, regis.gauvin@univ-lille.fr

\section{Author Contributions}

The manuscript was written thanks to contributions from all authors.

\section{ACKNOWLEDGMENT}

Chevreul Institute (FR 2638), CNRS, Ministère de l'Enseignement Supérieur et de la Recherche, Région Nord - Pas de Calais and FEDER are acknowledged for supporting and partially funding this work. Financial support from the TGIR RMN THC Fr3050 is gratefully acknowledged. 
1. Pearson, A. Aluminum Oxide (Alumina), Activated, in Kirk-Othmer Encyclopedia of Chemical Technology, Wiley-VCH, 2000.

2. Busca, G. Structural, Surface, and Catalytic Properties of Aluminas, Adv. Catal. 2014, 57, 319404.

3. Busca, G. The Surface of Transitional Aluminas: A Critical Review. Catal. Today, 2014, 226, 213.

4. Knözinger, H.; Ratnasamy, P. Catalytic Aluminas: Surface Models and Characterization of Surface Sites. Catal. Rev. Sci Eng. 1978, 17, 31-70.

5. Wagner, G. W.; Fry, R. A. Observation of Distinct Surface AlIV Sites and Phosphonate Binding Modes in $\gamma$-Alumina and Concrete by High-Field ${ }^{27} \mathrm{Al}$ and ${ }^{31} \mathrm{P}$ MAS NMR, J. Phys. Chem. C 2009, $113,13352-13357$.

6. See for instance: Morterra, C., Magnacca, G. A Case Study: Surface Chemistry and Surface Structure of Catalytic Aluminas, as Studied by Vibrational Spectroscopy of Adsorbed Species. Catal. Today, 1996, 27, 497-532.

7. De Canio, E. C.; Edwards, J. C.; Bruno, J. W. Solid-State ${ }^{1} \mathrm{H}$ MAS NMR Characterization of $\gamma$ Alumina and Modified $\gamma$-Aluminas. J. Catal. 1994, 148, 76-83.

8. Morris H. D.; Ellis, P. D. ${ }^{27}$ Al Cross Polarization of Aluminas. The NMR Spectroscopy of Surface Aluminum Atoms, J. Am. Chem. Soc. 1989, 111, 6045-6049.

9. Coster, D.; Blumenfeld, A. L.; Fripiat, J. J. Lewis Acid Sites and Surface Aluminum in Aluminas and Zeolites: A High-Resolution NMR Study J. Phys. Chem. 1994, 98, 6201-6211.

10. Barrow, N. S., Scullard, A.; Collis, N. Surface Selective ${ }^{1} \mathrm{H}$ and ${ }^{27}$ Al MAS NMR Observations of Strontium Oxide Doped $\gamma$-Alumina, Johnson Matthey Technol. Rev., 2016, 60, 90-97.

11. Paluch, P.; Potrzebowska, N.; Ruppert, A. M.; Potrzebowski, M. J. Application of ${ }^{1} \mathrm{H}$ and ${ }^{27} \mathrm{Al}$ Magic Angle Spinning Solid State NMR at $60 \mathrm{kHz}$ for Studies of Au and Au-Ni Catalysts Supported on Boehmite/Alumina, Solid State Nucl. Magn. Reson. 2017, 84, 111-117.

12. Ashbrook, S. E.; Wimperis, S. Spin-Locking of Half-Integer Spin Nuclei. J. Chem. Phys. 2009, $131,194509$.

13. Trébosc, J.; Hu, B.; Amoureux, J.-P.; Gan, Z. Through-space R ${ }^{3}$-HETCOR experiments between spin-1/2 and half-integer quadrupolar nuclei in solid-state NMR. J. Magn. Reson., 2007, 186, 220227.

14. Grekov, D.; Vancompernolle, T.; Taoufik, M.; Delevoye, L.; Gauvin, R. M. Solid-State NMR of Quadrupolar Nuclei for Investigations into Supported Organometallic Catalysts: Scope and Frontiers, Chem. Soc. Rev., 2018, 47, 2572-2590.

15. Giovine, R.; Trébosc, J.; Pourpoint, F.; Lafon, O.; Amoureux, J.-P. Magnetization Transfer from Protons to Quadrupolar Nuclei in Solid-State NMR using PRESTO or Dipolar-Mediated Refocused INEPT Methods. J. Magn. Reson. 2019, 299, 109-123.

16. Perras, F. A.; Kobayashi, T.; Pruski, M.; PRESTO Polarization Transfer to Quadrupolar Nuclei: Implications for Dynamic Nuclear Polarization. Phys.Chem.Chem.Phys., 2015, 17, 22616-22622.

17. Venkatesh, A.; Hanrahan, M. P.; Rossini, A. J. Proton Detection of MAS Solid-State NMR Spectra of Half-Integer Quadrupolar Nuclei, Solid State Nucl. Magn. Reson. 2017, 84, 171-181.

18. Tricot, G.; Lafon, O.; Trébosc, J.; Delevoye, L. ; Méar, F.; Montagne, L.; Amoureux, J.-P. Structural Characterisation of Phosphate Materials: New Insights into the Spatial Proximities between Phosphorus and Quadrupolar Nuclei using the D-HMQC MAS NMR Technique. Phys. Chem. Chem. Phys. 2011, 13, 16786-16794.

19. Mazoyer, E.; Trébosc, J.; Baudouin, A.; Boyron, O.; Pelletier, J.; Basset, J.-M.; Vitorino, M. J.; Nicholas, C. P.; Gauvin, R. M.; Taoufik, M.; Delevoye, L. Heteronuclear NMR Correlations to 
Probe the Local Structure of Catalytically Active Surface Aluminum Hydride Species on $\gamma$ Alumina. Angew. Chem. Int. Ed. 2010, 49, 9854-9858.

20. Jezequel, M.; Dufaud, V.; Ruiz-Garcia, M. J.; Carrillo-Hermosilla, F.; Neugebauer, U.; Niccolai, G. P.; Lefebvre, F.; Bayard, F.; Corker, J.; Fiddy, S.; Evans, J.; Broyer, J.-P.; Malinge, J.; Basset, J.-M.; Supported Metallocene Catalysts by Surface Organometallic Chemistry. Synthesis, Characterization, and Reactivity in Ethylene Polymerization of Oxide-Supported Mono- and Biscyclopentadienyl Zirconium Alkyl Complexes: Establishment of Structure/Reactivity Relationships, J. Am. Chem. Soc. 2001, 123, 3520-3540.

21. Brinkmann, A.; Kentgens, A. P. M. Proton-Selective ${ }^{17} \mathrm{O}^{-1} \mathrm{H}$ Distance Measurements in Fast Magic-Angle-Spinning Solid-State NMR Spectroscopy for the Determination of Hydrogen Bond Lengths. J. Am. Chem. Soc. 2006, 128, 14758-14759.

22. Taoufik, M.; Szeto, K.C.; Merle, N.; Del Rosal, I.; Maron, L.; Trébosc, J.; Tricot, G.; Gauvin, R. M.; Delevoye, L. Heteronuclear NMR Spectroscopy as a Surface-Selective Technique: A Unique Look at the Hydroxyl Groups of $\gamma$-Alumina. Chem. Eur. J., 2014, 20, 4038-4046.

23. Bryant, P. L.; Harwell, C. R.; Mrse, A. A.; Emery, E. F.; Gan, Z.; Caldwell, T.; Reyes, A. P.; Kuhns, P.; Hoyt, D. W.; Simeral, L. S.; Hall, R. W.; Butler, L. G. Structural Characterization of MAO and Related Aluminum Complexes. 1. Solid-State ${ }^{27} \mathrm{Al}$ NMR with Comparison to EFG Tensors from ab Initio Molecular Orbital Calculations, J. Am. Chem. Soc. 2001, 123, 1200912017.

24. Vega, A. J. CP-MAS of Quadrupolar S= 3/2 Nuclei. J. Magn. Reson., 1992, 96, 50-68.

25. Szeto, K. C.; Gallo, A.; Hernández-Morejudo, S.; Olsbye, U.; Lefebvre, F.; Gauvin, R. M.; Delevoye, L.; Scott, S. L.; Taoufik, M. Selective grafting of Ga( $i$-Bu $)_{3}$ on mesoporous H-ZSM-5 by surface organometallic chemistry for catalytic propane aromatization. J. Phys. Chem. C, 2015, 119, 26611-26619.

26. Gallo, A.; Fong, A.; Szeto, K. C.; Rieb, J.; Delevoye, L.; Gauvin, R. M.; Taoufik, M.; Peters, B.; Scott, S. L. Ligand exchange-mediated activation and stabilization of a Re-based olefin metathesis catalyst by chlorinated alumina. J. Am. Chem. Soc., 2016, 138, 12935-12947.

27. Zhang, F.; K. C. Szeto, K. C.; Taoufik, M.; Delevoye, L.; Gauvin, R. M.; Scott S. L. Enhanced Metathesis Activity and Stability of Methyltrioxorhenium on Amorphous Alumina: Role of the Local Grafting Environment. J. Am. Chem. Soc., 2018, 140, 13854-13868.

28. Mirhej, M.E. Proton Spin Relaxation by Paramagnetic Molecular Oxygen, Can. J. Chem., 1965, 43, 1130-1139.

29. Froix, M. F.; Goedde, A. O. Effect of Molecular Oxygen on the N.M.R. Relaxation Time of Some Aromatic Polymers, Polymer, 1976, 17, 758-760.

30. Klinowski, J.; Carpenter, T. A.; Thomas, J. M. The Origin of ${ }^{29}$ Si Spin-Lattice Relaxation in Zeolites: a Means of Rapide Acquisition of N.M.R. Spectra and of Probing Internal Sites in Microporous Catalysts, J. Chem. Soc., Chem. Commun., 1986, 956-958.

31. Wischert, R.; Florian, P.; Copéret, C.; Massiot, D.; Sautet, P. Visibility of Al Surface Sites of $\gamma-$ Alumina: A Combined Computational and Experimental Point of View. J. Phys. Chem C 2014, $118,15292-15299$.

32. Joubert, J.; Delbecq, F.; Sautet, P.; Le Roux, E.; Taoufik, M.; Thieuleux, C.; Blanc, F.; Copéret, C.; Thivolle-Cazat, J.; Basset, J.-M. Molecular Understanding of Alumina Supported Single-Site Catalysts by a Combination of Experiment and Theory, J. Am. Chem. Soc. 2006, 128, 9157-9169.

33. Vimont, A.; Lavalley, J. C.; Sahibed-Dine, A.; Otero Arean, C.; Rodriguez Delgado, M.; Daturi, M. Infrared Spectroscopic Study on the Surface Properties of $\gamma$-Gallium Oxide as Compared to Those of $\gamma$-Alumina, J. Phys. Chem. B 2005, 109, 9656-9664.

34. Liu, X.; Truitt, R. E. DRFT-IR Studies of the Surface of $\gamma$-Alumina, J. Am. Chem. Soc. 1997, 119, 9856-9860. 
35. Barrie, P. J. Distorted Powder Lineshapes in ${ }^{27}$ Al CP/MAS NMR Spectroscopy of Solids. Chem. Phys. Lett. 1993, 208, 486-490.

36. Fernandez, C.; Delevoye, L.; Amoureux, J.-P.; Lang, D.P.; Pruski, M. ${ }^{27} \mathrm{Al}\left\{{ }^{1} \mathrm{H}\right\}$ Cross Polarization Triple-Quantum Magic Angle Spinning NMR, J. Am. Chem. Soc. 1997, 119, 6858-6862.

37. Harris, R. K.; Olivieri, A. C. Quadrupolar Effects Transferred to Spin- $1 / 2$ Magic-Angle Spinning Spectra of Solids. Prog. Nucl. Magn. Reson. Spectrosc. 1992, 24, 435-456.

38. Delevoye, L.; Trébosc, J.; Gan, Z.; Montagne, L.; Amoureux, J.-P. Resolution enhancement using a new multiple-pulsedecoupling sequence for quadrupolar nuclei J. Magn. Reson. 2007, 186, 9499.

39. Severn, J. R.; Chadwick, J. C.; Duchateau, R.; Friederichs, N. "Bound but Not Gagged" Immobilizing Single-Site $\alpha$-Olefin Polymerization Catalysts. Chem. Rev. 2005, 105, 4073-4147.

40. Dahmen, K.-H.; Hedden, D.; Burwell, R. L.; Marks, T. J. Organometallic Molecule-Support Interactions. Highly Active Organozirconium Hydrogenation Catalysts and the Formation of Cationic Species on Alumina Surfaces Langmuir 1988, 4, 1212-1214.

41. Ahn, H.; Nicholas, C. P.; Marks, T. J. Surface Organozirconium Electrophiles Activated by Chemisorption on "Super Acidic" Sulfated Zirconia as Hydrogenation and Polymerization Catalysts. A Synthetic, Structural, and Mechanistic Catalytic Study. Organometallics 2002, 21, 1788-1806.

42. Nicholas, C. P.; Ahn, H.; Marks, T. J. Synthesis, Spectroscopy, and Catalytic Properties of Cationic Organozirconium Adsorbates on "Super Acidic" Sulfated Alumina. "Single-Site" Heterogeneous Catalysts with Virtually 100\% Active Sites, J. Am. Chem. Soc. 2003, 125, 43254331.

43. Detailed investigation on the alumina-dimethylzirconocene paper will be described in a forthcoming paper. We are of course aware that in addition to the chemistry mentioned here, ZrMe transfer onto the surface occurs, forming Al-Me species. This is masked thanked to the deuteration of the zirconium methyl groups.

44. Carnahan, S. L.; Lampkin, B. J.; Naik, P.; Hanrahan, P. M.; Slowing, I. I.; VanVeller, B.; Wu, G. ; Rossini, A. J., Probing O-H Bonding through Proton Detected ${ }^{1} \mathrm{H}^{-17} \mathrm{O}$ Double Resonance SolidState NMR Spectroscopy, J.Am.Chem.Soc. 2019, 141, 441-450

45. Wisser, D.; Karthikeyan, G.; Lund, A.; Casano, G.; Karoui, H.; Yulikov, M.; Menzildjian, G.; Pinon, A.C.; Purea, A.; Engelke, F.; et al. BDPA-Nitroxide Biradicals Tailored for Efficient Dynamic Nuclear Polarization Enhanced Solid-State NMR at Magnetic Fields up to 21.1 T J. Am. Chem. Soc. 2018, 140, 13340-13349 


\section{Graphic entry for the Table of Contents}

$\gamma=\mathbb{A l}_{2} \mathrm{O}_{3}$ surface through MAS NMR

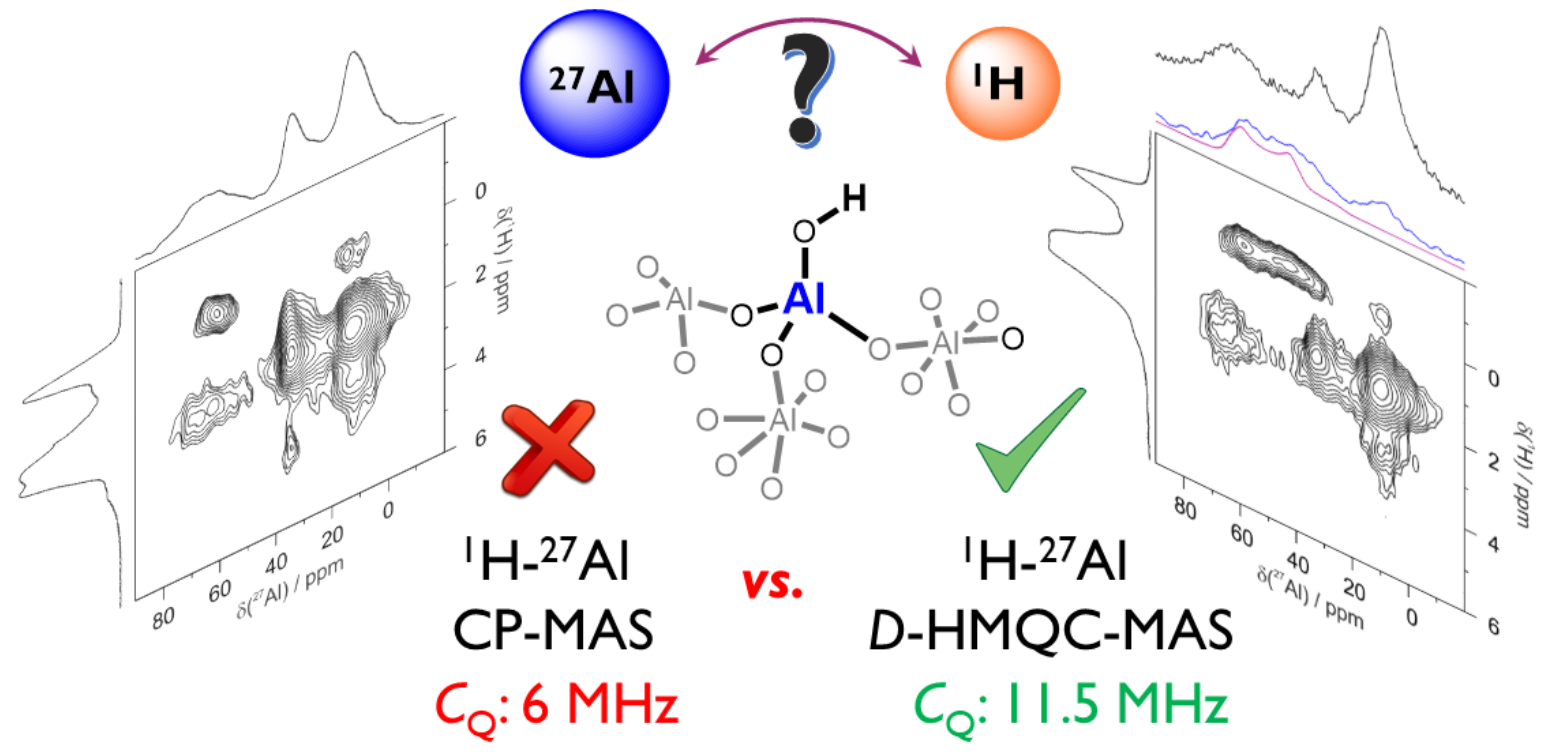

